\title{
Implementasi Metode User Centered Design (Ucd) Pada Pembangunan Sistem Penyediaan Obat Berbasis Android
}

\author{
Muhammad Rifai \& Muhamad Akbar \\ Fakultas Teknik Ilmu Komputer, Universitas Bina Darma \\ Email: muh.boy39.mr@gmail.com
}

\begin{abstract}
The rapid development of information technology has an impact on behavior. The system is linked together to facilitate the flow of information, through a variety of androids, users are growing, and are very familiar with this technology is open to providing developers to create an application. User Center Design (UCD) is a design that is used because it presents the best approach if it describes from the initial stages of an interactive process. Information about the provision of medicine is desired without the need to go to his place.
\end{abstract}

Keyword: Information Technology, System, Android, User Centered Design, Provision of medicine, User

\section{Pendahuluan}

Kemajuan teknologi dan ilmu pengetahuan saat ini mulai mengubah cara piker dan kerja kita, kegiatan-kegiatan seperti kegiatan bisnis yang dulunya dapat dilakukan secara manual mulai tergantikannya dengan sebuah teknologi. Penggunaan teknologi pada berbagai bidang juga terus berkembang termasuk dalam bidang obat-obatan, teknologi ini sangat dibutuhkan untuk menghasilkan informasi yang cepat, akurat, dan memudahkan.

Perkembangan teknologi informasi yang semakin pesat berdampak pada perilaku banyak orang yang ingin memenuhi kebutuhan informasi yang lebih cepat dan murah tentunya, selain itu menuntut juga para pemberi informasi untuk memiliki sebuah sistem, dimana informasi yang disajikan bisa dengan mudah dan cepat didapatkan.

Sistem dihubungkan bersama untuk memudahkan aliran informasi, materi atau energi untuk mencapai suatu tujuan. Informasi melalui android yang beragam, penggunanya terus bertambah, dan sangat akrab dengan teknologi ini serta informasi mengenai persedian obat-obatan yang di inginkan tanpa perlu ke tempat-nya ini akan lebih mudah dan cepat untuk orang-orang melalui sebuah aplikasi. Untuk membuat sistem tersebut membutuhkan metode khusus, agar sesuai dengan harapan pengguna.

User Centered Design (UCD) merupakan metode dengan pengguna sebagai pusat dari proses pembangunan sistem, dan rancangan akan dievaluasi oleh pengguna dengan begini sistem akan sesuai dengan harapan pengguna.

\section{Tinjauan Literatur}

Tinjauan penelitian terdahulu ini memuat hasil-hasil penelitian sejenis terdahulu yang menginsipirasi atau melandasi pelaksanaan penelitian ini dan menjadi literatur yang berhubungan dengan penelitian yang akan dilakukan, seperti landasan teori dan penelitian sebelumnya berikut ini tabelnya: 
Tabel 2.1 Tabel Penelitian Sebelumnya

\begin{tabular}{|c|c|c|c|}
\hline JUDUL & TAHUN & METODE & TERBIT \\
\hline $\begin{array}{l}\text { Perancangan Kamus Muslim Berbasis } \\
\text { Smartphone Android Dengan Metode } \\
\text { User Centered Design (UCD).(Iwan } \\
\text { Purnama) }\end{array}$ & 2017 & User Centered Design & $\begin{array}{l}\text { AMIK, } \\
\text { Labuhanbatu }\end{array}$ \\
\hline $\begin{array}{l}\text { Penerapan Metode User Centered Design } \\
\text { (UCD) Pada Sistem Pemesanan Buana } \\
\text { Menu Kuliner Nusantara Berbasis } \\
\text { Mobile Android.(Bayu Priyatna) }\end{array}$ & 2019 & User Centered Design & $\begin{array}{l}\text { Universitas } \\
\text { Buana } \\
\text { Perjuangan, } \\
\text { Karawang } \\
\end{array}$ \\
\hline $\begin{array}{l}\text { Rancangan Prototipe Mockup Sistem } \\
\text { Informasi Manajemen Pada Biro Travel } \\
\text { UINSA.(Siti Nurazizah) }\end{array}$ & 2018 & User Centered Design & $\begin{array}{l}\text { UINSA, } \\
\text { Surabaya }\end{array}$ \\
\hline $\begin{array}{l}\text { Implementasi } \text { Metode User Centred } \\
\text { Design Pada Pengembangan Gim } \\
\text { Matematika Berbasis Desktop Bagi } \\
\text { Siswa Sd Negeri 1 Candiwulan } \\
\text { Implementasi Metode User Centred } \\
\text { Design Pada Pengembangan Gim } \\
\text { Matematika Berbasis Desktop Bagi } \\
\text { Siswa Sd Negeri } 1 \text { Candiwulan.(Nagita } \\
\text { Rahman) }\end{array}$ & 2018 & User Cente & $\begin{array}{l}\text { Universitas } \\
\text { Islam } \\
\text { Indonesia, } \\
\text { Yogyakarta }\end{array}$ \\
\hline $\begin{array}{lll}\text { Sistem } & \text { Informasi } & \text { Pengelolaan } \\
\text { Obat(Studi Kasus Apotek Joint Farma, } \\
\text { Yogyakarta).(Olivia Dian Kusumawati) }\end{array}$ & 2009 & $\begin{array}{l}\text { FAST, Fast for th } \\
\text { Application of Systems } \\
\text { Thinking }\end{array}$ & $\begin{array}{l}\text { Universitas } \\
\text { Sanata Dharma, } \\
\text { Yogyakarta }\end{array}$ \\
\hline $\begin{array}{llr}\text { Aplikasi } & \text { Pemesanan } & \text { Barang } \\
\text { Menggunakan } & \text { Metode User Centered } \\
\text { Design (UCD) Berbasis Android.(Dwi } \\
\text { Yuli Haryanto) }\end{array}$ & 2009 & User Centered Design & $\begin{array}{l}\text { Universitas } \\
\text { Dian } \\
\text { Nuswantoro, } \\
\text { Semarang }\end{array}$ \\
\hline $\begin{array}{l}\text { Perancangan Desain User dan User } \\
\text { Experience Pada Aplikasi SIAKAD } \\
\text { Dengan Menggunakan Metode User } \\
\text { Centered Design (UCD) Pada Universitas } \\
\text { Islam Negeri Sunan Ampel Surabaya.(A. } \\
\text { Iqbal Yunus) }\end{array}$ & 2018 & User Centered Design & $\begin{array}{l}\text { Universitas } \\
\text { Islam Negeri } \\
\text { Sunan Ampel, } \\
\text { Surabaya }\end{array}$ \\
\hline
\end{tabular}

Penjelasan yang telah dijabarkan terkait dengan penelitian sejenis tersebut, maka terdapat relevansi dan perbedaan dengan penelitian penulis. Pada penelitian yang dilakukan oleh penulis akan dijelaskan sebagai berikut:

1. Metode pembangunan sistem menggunakan metode User Centered Design (UCD). Dengan menggunakan metode UCD yang menampilkan pendekatan terbaik jika menguraikan dari tahapan awal proses yang interaktif dimana langkah perancangan dan evaluasi dibuat dalam permulaan proyek sampai implementasi maka penulis harus memahami terkait dengan kebutuhan yang benar-benar sesuai dengan pengguna sistem.

2. Analisis menggunakan UML (Unified Model Language) dalam bentuk Diagram Use Case, Diagram Activity, Diagram Sequence, dan Diagram Class. Dengan menggunakan analisis UML maka penulis dapat memastikan dan memahami terkait dengan kebutuhan pengguna dan proses yang ada dalam bentuk yang lebih konkrit. 
3. Perancangan antarmuka awal dilakukan dengan menggunakan prototipe. Setelah itu dilakukan implementasi menggunakan ANDROID STUDIO dengan bahasa pemrograman JAVA.

4. Perancangan dan evaluasi dilakukan dengan metode UCD berbasis ISO 9241210(2010).

\subsection{Sistem}

Menurut Zakky (2018) yang terdapat pada website zonareferensi.com Secara umum sistem berasal dari bahasa Latin (systèma) dan bahasa Yunani (sustēma) adalah suatu kesatuan yang terdiri komponen atau elemen yang dihubungkan bersama untuk memudahkan aliran informasi, materi atau energi untuk mencapai suatu tujuan. Istilah ini sering dipergunakan untuk menggambarkan suatu set entitas yang berinteraksi, dimana suatu model matematika sering kali bisa dibuat.

Sistem juga merupakan kesatuan bagian-bagian yang saling berhubungan yang berada dalam suatu wilayah serta memiliki item-item penggerak, contoh umum misalnya seperti negara. Negara merupakan suatu kumpulan dari beberapa elemen kesatuan lain seperti provinsi yang saling berhubungan sehingga membentuk suatu negara di mana yang berperan sebagai penggeraknya yaitu rakyat yang berada dinegara tersebut. Sedangkan sistem menurut Jogiyanto (2005:1-2), "Sistem adalah suatu jaringan kerja dari prosedurprosedur yang saling berhubungan, berkumpul Bersama-sama untuk melakukan suatu kegiatan atau untuk menyelesaikan suatu sasaran yang tertentu".

\subsection{User Centered Design (UCD)}

User Centered Design (UCD) merupakan metode penelitiaan yang pembangunan sistemnya berpusat pada pada pengguna. Menurut Siti Nurazizah (2018) "Pendekatan pengembangan sistem interaktif yang fokus pengembangan sistemnya adalah memusatkan perhatian pada penggun".

Dalam Metode ini pengembang sebuah sistem yang berfokus pada pengguna memiliki tahapan-tahapan seperti berikut:

1. Memahami dan mengindetifikasi kontek pengguna dalam penggunaan, kebutuhan dan teknisnya untuk mendinisikan konteks sistem yang digunakan.

2. Mengindetifikasi permintaan pengguna pada setiap desain sistem serta permintaan lainnya untuk suatu produk atau sistem adalah aktifitas utama.

3. Solusi desain produk merupakan hasil dari gambaran konteks yang digunakan, hasil dari setiap evaluasi awal, desain, serta pengalaman dan pengetahuan tim desain.

4. Mengevaluasi desain yang telah dibuat. Dengan adanya evaluasi ini kebutuhan pengguna dapat diperoleh dengan pemahaman yang lebih baik.

\subsection{Bahasa Pemrograman}

Bahasa yang dipakai untuk menginstruksikan komputer disebut bahasa pemrograman. Ada 2 jenis bahasa pemrograman terdiri dari bahasa tingkat tinggi \& bahasa tingkat rendah. Kita kenal diantaranya: Basic, Algol, Cobol, Pascal, RPG, SNOBOL, APL, LISP, GPSS, ADA, DEAL dan sebagainya yang merupakan bahasa tingkat tinggi.

Bahasa yang dimengerti oleh mesin komputer adalah intruksi dalam bahasa mesin (Machine Language) yang merupakan bahasa tingkat rendah, jadi bahasa tingkat tinggi 
yang kita sebutkan diatas agar dapat dimengerti oleh komputer haruslah diterjemahkan lebih dahulu oleh kompilator. Ciri dari bahasa tingkat rendah adalah bahwa cara penulisanya intruksinya sangat mendekati bentuk intruksi-intruksi dalam bahasa mesin. Bahasa tersebut dalam bentuk kode HEXA yang sulit bagi sebagian untuk mengertinya.

Komputer bekerja secara elektronik, maka ia tidak dapat menerima masukan berupa tulisan kertas begitu saja. Ia baru dapat membaca informasi dalam bentuk kombinasi bitbit listrik. Kombinasi-kombinasi tersebut didalam komputer sering disebut sebagai kode mesin (Machine kode) yang tidak lain adalah bahasa computer itu sendiri, yaitu kodekode yang dikenal oleh computer, manusia pun dapat mengerti kode-kode tersebut hanya tersusun dari angka nol dan satu yang berderet panjang sekali.

Jadi komputer sudah mengenal istilah bahasa, yaitu serangakaian kombinasi kode yang digunakan untukmenyampaikan rumus. Didalam bahasa program, perintahperintah/rumus-rumus kebanyakan dituliskan dalam bahasa inggris. Dari bahasa inggris yang sama itu telah dibuat orang berbagai macam cara memberikan perintah pada komputer.

\subsubsection{Java}

Menurut definisi Sun Microsystem, di dalam buku M. Shalahuddin dan Rosa A.S. (2010:1), Java adalah nama sekumpulan teknologi untuk membuat dan menjalankan perangkat lunak pada komputer yang berdiri sendiri (standalone) ataupun pada lingkungan jaringan. Java berdiri di atas sebuah mesin penterjemah (interpreter) yang diberi nama Java Virtual Machine (JVM). JVM inilah yang akan membaca kode bit (bytecode) dalam file .class dari suatu program sebagai representasi langsung program yang berisi bahasa mesin. Oleh karena itu bahasa Java disebut sebagai bahasa pemrograman yang portable karena dapat dijalankan pada berbagai sistem operasi, asalkan pada system operasi tersebut terdapat JVM.

Alasan utama pembentukan bahasa Java adalah untuk membuat aplikasi-aplikasi yang dapat diletakkan di berbagai macam perangkat elektronik, sehingga Java harus bersifat tidak bergantung pada platform (platform independent). Itulah yang menyebabkan dalam dunia pemrograman Java dikenal adanya istilah "write once, run everywhere" yang berarti kode program hanya ditulis sekali, namun dapat dijalankan di bawah kumpulan pustaka (platform) manapun, tanpa harus melakukan perubahan kode program.

\subsection{Database}

Menurut Sutarman (2012:15), Database sekumpulan file yang saling berhubungan dan terorganisasi atau kumpulan record-record yang menyimpan data dan hubungan diantaranya.

Menurut Ladjamudin (2013:129), Database adalah sekumpulan data store (bisa dalam jumlah yang sangat besar) yang tersimpan dalam magnetic disk, oftical disk, magnetic drum, atau media penyimpanan sekunder lainya.

Dari pengertian diatas penulis menyimpulkan Database adalah sekumpulan file yang saling berhubungan yang menyimpan data dan tersimpan dalam sebuah media penyimpanan. 


\subsubsection{SQLite}

Menurut Hendry (2015), SQLite merupakan sebuah sistem manajemen basis data relasional yang bersifat $A C I D$-compliant dan memiliki ukuran pustaka kode yang relatif kecil, ditulis dalam bahasa C. SQLite merupakan proyek yang bersifat public domain yang dikerjakan oleh D. Richard Hipp. Tidak seperti pada paradigma client-server umumnya, Inti SQLite bukanlah sebuah sistem yang mandiri yang berkomunikasi dengan sebuah program, melainkan sebagai bagian integral dari sebuah program secara keseluruhan sehingga protokol komunikasi utama yang digunakan adalah melalui pemanggilan API secara langsung melalui bahasa pemrograman.

Mekanisme seperti ini tentunya membawa keuntungan karena dapat mereduksi overhead, latency times, dan secara keseluruhan lebih sederhana. Seluruh elemen basis data (definisi data, tabel, indeks, dan data) disimpan sebagai sebuah file. Kesederhanaan dari sisi desain tersebut bisa diraih dengan cara mengunci keseluruhan file basis data pada saat sebuah transaksi dimulai.

\section{Metode Penelitian}

Penelitian ini akan menggunakan tahapan dimana langkah dimulai awal sampai akhir dilakukannya penelitian. Tahapan ini dilakukan untuk mempermudah proses perancang dengan mengacu pada Metode User Centered Design. Metode UCD digunakan karena menampilkan pendekatan terbaik jika menguraikan dari tahapan awal proses yang interaktif dimana langkah perancangan dan evaluasi dibuat dalam permulaan proyek sampai implementasi.

\subsection{User Centered Design}

User Centered Design (UCD) merupakan metode penelitiaan yang pembangunan sistemnya berpusat pada pada pengguna. Pendekatan pengembangan sistem interaktif yang fokus pengembangan sistemnya adalah memusatkan perhatian pada penggun.

Dalam (ISO 9241-210:2010) terdapat 5 proses yaitu seperti gambar dibawah:

1. Plan the Human Centered Process

2. Specify the Context of Use

3. Specify User and Organisational Requirement.

4. Product Design Solutions

5. Evaluate Design Againt User Requirement

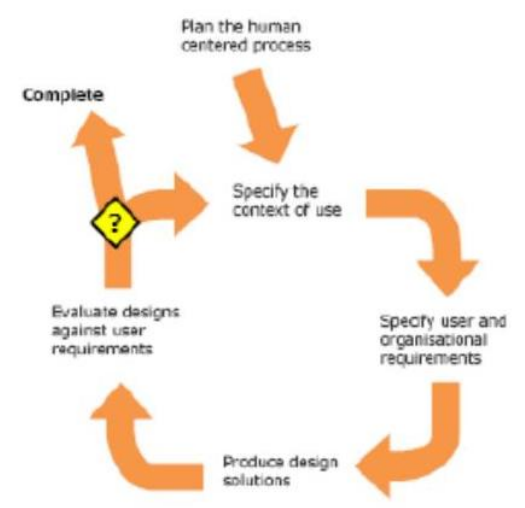


Gambar 1. Proses UCD []

\subsection{Unified Modeling Language (UML)}

Unified Modeling Language (UML) adalah pendekatan terstruktur memiliki tool-tool perancangan yang di kenal secara luas serta menjadi standar umum, seperti DFD (Data Flow Diagram), ERD (Entity Relationship Diagram), bagan terstruktur (structure chart), diagram alir flow chart.[4]

Diagram Unified Modeling Language (UML) terdapat 7 diagram yaitu :

\section{Class Diagram}

2.Object Diagram

\section{Use Case Diagram}

\section{Sequence Diagram}

\section{Statechart Diagram}

\section{Activity Diagram}

\subsection{Prototipe}

Prototipe merupakan sarana inti yang digunakan untuk mengeksplorasi dan mengekspresikan desain dalam interaktif artefak komputer yang diakui secara luas. Memilih jenis prototipe yang tepat untuk dibangun adalah sebuah seni tersendiri, dan mengkomunikasikan tujuan terbatasnnya kepada berbagai khalayak merupakan aspek penting dari penggunaannya. terdapat tiga jenis rancangan tampilan sebagaimana penjelasan berikut ini:

\section{Wireframe}

\section{Mockup}

\section{Protoype}

\section{Hasil dan Pembahasan}

Berbadasarkan perancangan Prototipe dan diskusikan dengan pengguna sudah berkomitmen apakah perancangan sudah pas atau ada hal yang yang ingin ditambahkan. Kemudian (Evaluate Design Against User Requirements) diuji dan evaluasi pada smartphone maka hasil sesuai dengan keinginan pengguna.

\subsection{Analisis}

Analisis yang di lakukakan sesuai dengan metode User Centered Design (UCD) dimana kita melakukan analisis untuk mengindetifikasi untuk apa dan dalam kondisi seperti apa mereka akan menggunakan sistem ini, serta mengindetifikasi kebutuhan pada pengguna melalui wawancara dan kuisioner.

\subsubsection{Wawancara}

Wawancara dilakukan kepada pengguna atau orang yang sudah berkomitmen pada projek ini dengan tujuan dengan mengumpulkan informasi dan data mengenai pembangunan sistem ini, serta memahami dan menentukan konteks pengguna.

Kemajuan teknologi saat ini mulai mengubah cara pikir dan kerja kita, penggunaan 
teknologi seperti android yang telah banyak digunakan menjadi sebuah teknologi yang bisa digunakan dalam berbagai bidang.Bidang obat-obatan atau kesehatan sangat diperlukan sekarang. Teknologi ini melalaui android memberikan informasi daftar obat, toko obat, daftar penyakit, dan berita kesehatan.

Maka dari itu pembuatan sistem penyediaan obat yang berbasis pada Platform Android dengan menggunakan metode User Centered Design (UCD) dimana pengguna akan mudah untuk digunakan dan dimanapun.

Dari konteks diatas sistem penyediaan obat yang akan dibuat dengan skenario sebagai berikut:

1. Pengguna akan menggunakan sistem ini melalui Platform Android yang telah banyak digunakan.

2. Sistem ini akan memberikan infromasi daftar penyakit beserta obat-obatnya.

3. Sistem ini akan menampilkan informasi Toko atau Apotek Obat terdekat dari pengguna.

4. Sistem ini menginfokan berita tentang Kesehatan.

5. Sistem ini akan mencakup hal-hal yang diperlukan.

\subsubsection{Kuesioner}

Menentukan kebutuhan pengguna dan oraganisasi (Specify User and Oraganisational Requirment) merupakan langkah kedua dalam metode User Centered Design (UCD), pada tahap ini menjelaskan kebutuhan pengguna dan sistem.

Hasil analisis dari kebutuhan pengguna melalui kuesioner Implementasi Metode User Centered Design (UCD) pada Pembangunan Sistem Penyediaan Obat Berbasis Android pada tabel berikut ini :

Tabel 1. Kuesioner Kebutuhan Pengguna

\begin{tabular}{|c|l|c|c|}
\hline \multirow{2}{*}{ No } & \multicolumn{1}{|c|}{ Pertanyaan } & \multicolumn{2}{|c|}{ Jawaban } \\
\cline { 3 - 4 } & & $\begin{array}{c}\text { Jumlah } \\
\text { (Ya) }\end{array}$ & $\begin{array}{c}\text { Jumlah } \\
\text { (Tidak) }\end{array}$ \\
\hline 1 & Apakah warna aplikasi akan menggunakan warna hijau? & 21 & 3 \\
\hline 2 & $\begin{array}{l}\text { Apakah anda setuju aplikasi terdapat data obat-obatan, toko obat, } \\
\text { informasi Kesehatan, dan daftar penyakit? }\end{array}$ & 22 & 2 \\
\hline 3 & Apakah perlu mendetail sebuah data yang akan ditampilakan? & 20 & 4 \\
\hline
\end{tabular}




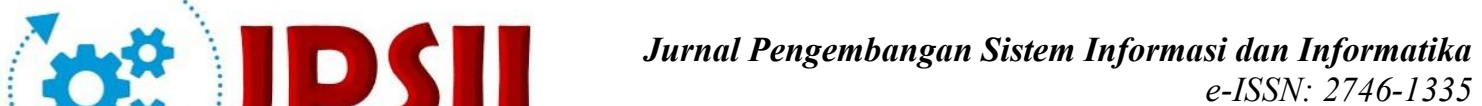 \\ Vol. 1, No. 4, October 2020}

\begin{tabular}{|c|l|c|c|}
\hline 4 & Apakah anda perlu menemukan lokasi toko dengan Maps? & 24 & 0 \\
\hline 5 & Apakah informasi Kesehatan harus terupdate & 24 & 0 \\
\hline 6 & Apakah setuju background berwarna putih? & 22 & 2 \\
\hline 7 & Apakah perlu icon-icon yang familiar pada setiap menu? & 24 & 0 \\
\hline
\end{tabular}

3.1.3 Unified Modeling Language (UML)

Product Design Solution merupakan langkah yang digunakan untuk mengidentifikasi dari analisis kebutuhan pengguna. Pada tahap ini peneliti akan mengidentifikasi kebutuhan pengguna menggunakan UML . Mulai dari diagram use case lalu membuat activity diagram sesuai use case yang telah ditentukan selanjutnya membuat class diagram lalu membuat sequence diagram dari masing-masing activity diagram dengan menambahkan field yang sesuai dengan analisis kebutuhan.

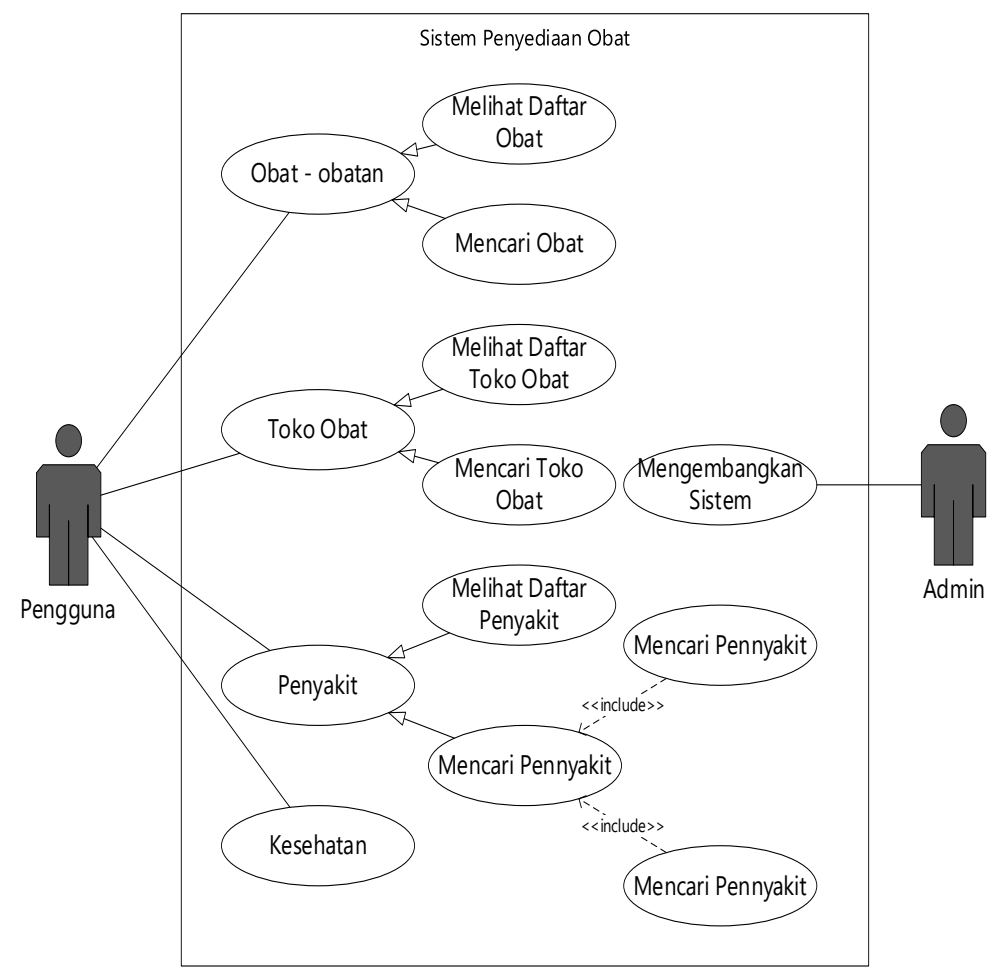

Gambar 2. Use Case Diagram

\subsubsection{Prototipe}

Prototipe perancangan dilakukan untuk membuat gambaran yang akan diterapkan kepada sistem sebelum dikembangkan lebih lanjut dengan tujuan agar gambaran antarmuka ini dapat umpan balik dari pengguna bahwa sistem telah sesuai dengan sistem. 

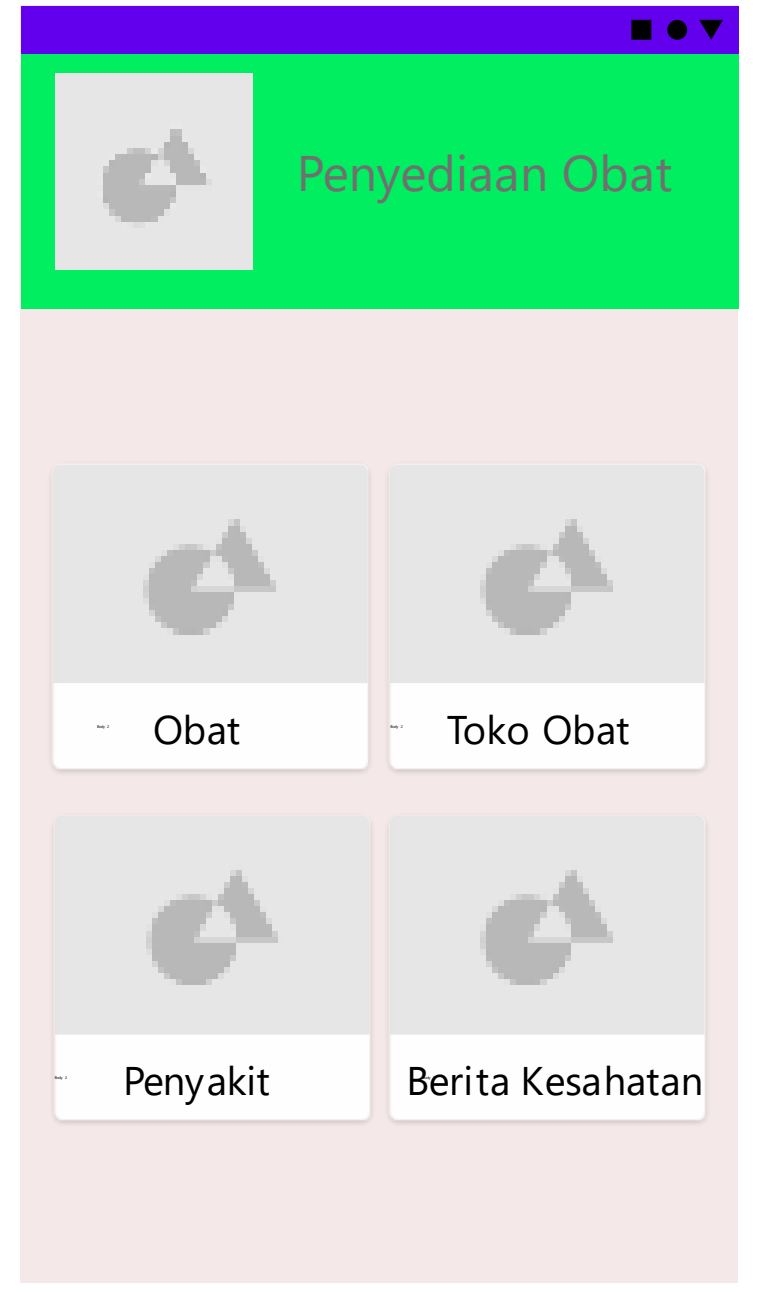

Gambar 3. Prototipe Halaman Utama

\subsection{Hasil}

Berbadasarkan perancangan Prototipe dan diskusikan dengan pengguna sudah berkomitmen apakah perancangan sudah pas atau ada hal yang yang ingin ditambahkan. Kemudian (Evaluate Design Against User Requirements) diuji dan evaluasi pada smartphone maka hasil sesuai dengan keinginan pengguna, berikut ini adalah tampilan dari aplikasi : 


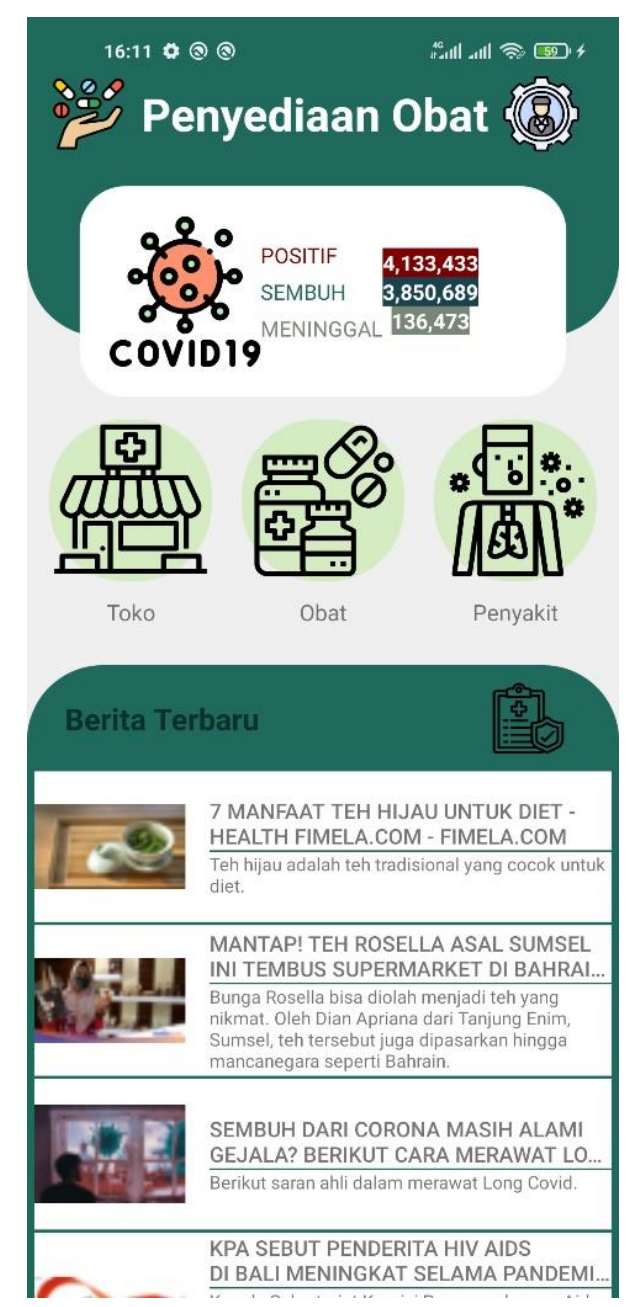

Gambar 4. Tampilan Halaman Utama

\subsection{Pembahasan}

Tahap ini merupakan pembahasan pengujian dan evaluasi dari rancangan sistem yang telah dibuat (Evaluate Design Against User Requirements). Pengujian dilakukan dengan menggunakan kuesioner dengan menyebarkan kepada pengguna responden untuk pengujian ini, hasil dari pengujian dari kuesioner sebagai berikut:

Tabel 2. Kuesioner Pengujian

\begin{tabular}{|c|l|c|c|}
\hline \multirow{2}{*}{ No } & \multicolumn{1}{|c|}{ Pertanyaan } & \multicolumn{2}{|c|}{ Jawaban } \\
\cline { 3 - 4 } & & $\begin{array}{c}\text { Jumlah } \\
\text { (Ya) }\end{array}$ & $\begin{array}{c}\text { Jumlah } \\
\text { (Tidak) }\end{array}$ \\
\hline 1 & Menu menu aplikasi Penyediaan Obat mudah dipahami & 20 & 4 \\
\hline 2 & Warna pada desain aplikasi Penyediaan Obat menarik & 22 & 2 \\
\hline 3 & $\begin{array}{l}\text { Penggantian halaman ke halaman lainnya tidak membutuhkan waktu } \\
\text { lama }\end{array}$ & 20 & 4 \\
\hline 4 & $\begin{array}{l}\text { Penggunaan aplikasi Penyediaan Obat sangat jelas dan mudah } \\
\text { digunakan }\end{array}$ & 20 & 4 \\
\hline
\end{tabular}




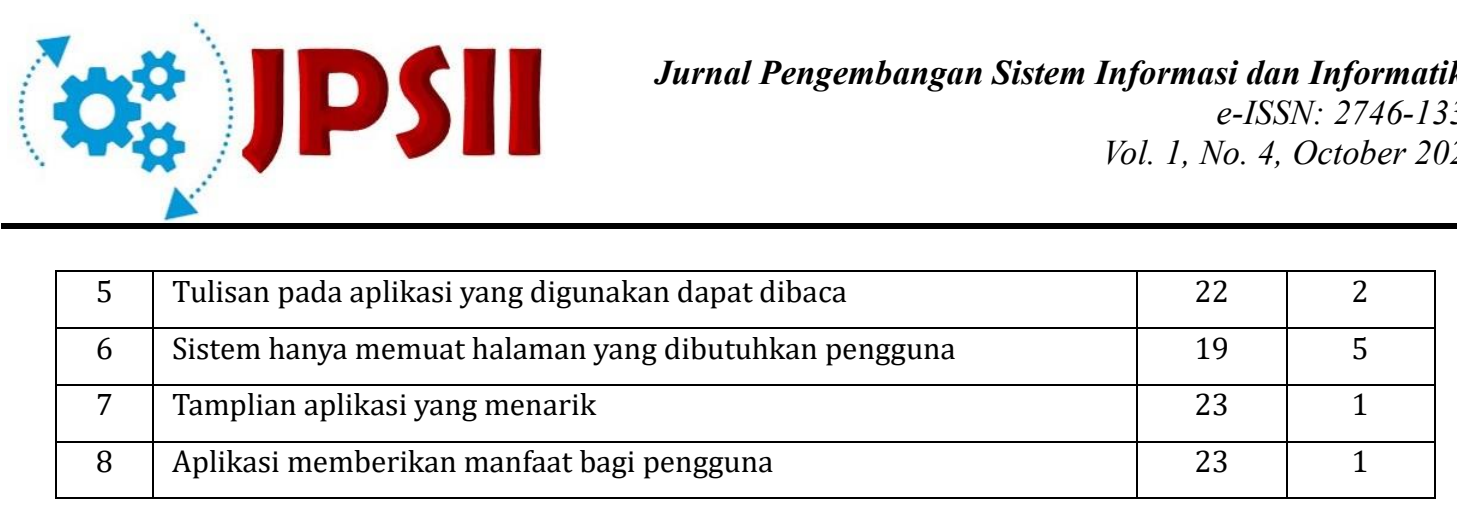

\section{Kesimpulan}

Kesimpulan dari penelitian dengan judul "Implementasi Metode User Centered Design (UCD) Pada Pembangunan Sistem Penyediaan Obat Berbasis Android” Sebagai berikut:

1. Penelitian ini mengimplementasikan metode User Centered Design dengan melakukan analisis hal-hal dibutuhkan lalu menentukan kebutuhan kemudian merancang.

2. Aplikasi yang digunakan pengguna bisa menampilkan daftar obat yang mendetail, daftar toko obat beserta lokasinya, daftar penyakit yag mendetail dan berita tentang kesehatan.

3. Pembangunan sistem ini dievaluasi dan diuji dengan smartphone serta melakukan kuesioner dari aplikasi ini bahwa sistem ini sudah memberikan sistem sesuai dengam pengguna..

\section{Referensi}

Antoni, D., Herdiansyah, M. I., Akbar, M., \& Sumitro, A. (2021). Pengembangan Infrastruktur Jaringan Untuk Meningkatkan Pelayanan Publik di Kota Palembang. JURNAL MEDIA INFORMATIKA BUDIDARMA, 5(4), 1652-1659.

Antoni, D., Jie, F., \& Abareshi, A. (2020). Critical factors in information technology capability for enhancing firm's environmental performance: case of Indonesian ICT sector. International Journal of Agile Systems and Management, 13(2), 159-181.

Antoni, D., \& Akbar, M. (2019). E-supply chain management value concept for the palm oil industry. Jurnal Sistem Informasi, 15(2), 15-29.

Antoni, D., Fikari, D., \& Akbar, M. (2018). The readiness of palm oil industry in enterprise resource planning. Telkomnika, 16(6), 2692-2702.

Fauzi, F., Dencik, A. B., \& Asiati, D. I. (2019). Metodologi Penelitian untuk manajemen dan akuntansi. Jakarta: Salemba Empat.

Priyatna, Bayu. (2019). Penerapan Metode User Centered Design (UCD) Pada Sistem Pemesanan Menu Kuliner Nusantara Berbasis Mobile Android. Universitas Buana Perjuangan, Karawang.

Nurazizah, Siti. (2018).Rancang Prototipe Mockup Sistem Informasi Manajemen Pada Biro Travel UINSA. UINSA, Surabaya.

Purnama, Iwan. (2017). Perancangan Kamus Muslim Berbasis Smartphone Android Dengan Metode User Centered Design (UCD). AMIK, Labuhanbatu.

Adi Nugroho, 2009, Rekayasa Perangkat Lunak Menggunakan UML dan Java. Yogyakarta : ANDI.

Houde, S., \& Hill, C. (1997). What do Prototype? Handbook of Human-Computer Interaction, 367-381. https://doi.org/10.1016/B978-044481862-1/50082-0. 
Bot, M. (2016). What's the difference between Wireframe, Prototype \& Mockup? https://medium.com//mockigbot/whats-the-difference-between-wireframe-prototype-mockup17615f77938f.

\section{Copyrights}

Copyright for this article is retained by the author(s), with first publication rights granted to the journal.

This is an open-access article distributed under the terms and conditions of the Creative Commons Attribution license (http://creativecommons.org/licenses/by/4.0/) 